\title{
Optimization of calculations of the effects of spill fires during accidents on linear equipment
}

\author{
Elena Andreevna Saltanaeva ${ }^{1}$, Andrey Vladimirovich Maister ${ }^{1, *}$ \\ ${ }^{1}$ Kazan State Energy University, Kazan, Russia
}

\begin{abstract}
The issue of industrial (in particular, fire) safety at hazardous production facilities is considered. The previously obtained optimization method is given for calculating the assessment of the influence of hazardous factors in the event of possible accidents on extended (linear) equipment during explosions of fuel-air mixtures. Optimization is based on accelerating the calculations of the potential damage probability of $Q_{n}\left(M_{0}\right)$ using transformed formulas containing a single instead of a double integral. The transformed formulas for calculating the double integral obtained in were used to optimize the calculations for the case of a spill fire based on the recommended probit function $\operatorname{Pr}$ used to estimate the damage to people by thermal radiation. As an example of calculations, a rectilinear fragment of a pipeline on a plane, presented as a segment of a straight line, is considered. To obtain an assessment of effectiveness, 1000 sets of source data characterizing various emergency situations were randomly generated. Based on the calculations for these data sets, statistical results are presented that characterize the effectiveness of the proposed optimization method: a graph of the values of the multiplicity of the reduction in calculation time using the converted formulas; average value and standard deviation of the multiplicity of reduction of calculation time; the maximum deviation of the values calculated by the original and converted formulas.
\end{abstract}

Key words: industrial safety, fire safety, spill fire, emergency scenario, combustion mode, probit function, optimization of numerical calculations.

\section{Introduction}

Industrial safety of hazardous production facilities is defined in Federal Law No. 116-FL not as a property or condition of hazardous production facilities themselves, but as a state of protection of the vital interests of individuals and society from accidents at hazardous production facilities and the consequences of these accidents [1].

Industrial safety in terms of protecting the interests (life and health) of the employee's personality is associated with labor protection, which, according to the Labor Code, is a system for preserving the life and health of workers in the course of labor activity, as well as preventing accidents, their localization, eliminating and mitigating their consequences [2].

The justification of safety for a hazardous production facility is a document containing information about the results of an accident risk assessment at a hazardous production facility and the associated threat, conditions for the safe operation of a hazardous production facility, requirements for operation, overhaul, conservation and liquidation of a hazardous production facility [3-6].

The main concept on which estimates of possible consequences are based is the concept of an
"Emergency Scenario" [7], which includes the structure of the describing data: Equipment, Hazardous Substance, Triggering Event, Combustion Mode, Meteorological Data, Calculated Results of Consequences [8].

The calculated results of the consequences include various sets of calculated values depending on the mode of combustion (explosion), including the characteristics of the combustion process and quantitative estimates of the possible effects on humans.

There are two approaches to describing the possible effects of hazardous accident factors - deterministic and probabilistic.

The deterministic approach assumes the presence of a discrete set of levels of the impact of the consequences of the accident, indicating the corresponding critical values of hazardous factors. For example, for the "Spill Fire" combustion mode, fixed levels of possible exposure to humans and the corresponding values of the critical intensity of thermal radiation were selected as follows:

1st level of damage. Intolerable pain after 3-5 s, (as well as burns of 1st degree after 6-8s, burns of 2nd degree after 12-16 s); The critical value of the hazard is the thermal radiation intensity of $10.5 \mathrm{~kW} / \mathrm{m}^{2}$.

*Corresponding author: elena maister@mail.ru 
2nd level of damage. Intolerable pain after 20-30 s (as well as burns of 1st degree after 15-20 s, burns of 2nd degree after 30-40 s); The critical value of the hazard is the thermal radiation intensity of $7.0 \mathrm{~kW} / \mathrm{m}^{2}$.

3rd level of damage. Safe for people in canvas clothing; the critical value of the hazard is the thermal radiation intensity of $4.2 \mathrm{~kW} / \mathrm{m}^{2}$.

4th level of damage. No negative effects for a long time; the critical value of the hazard is the thermal radiation intensity of $1.4 \mathrm{~kW} / \mathrm{m}^{2}$.

Thus, with a deterministic approach in assessing the risk of an accident for the indicated levels of damage, the radii of the corresponding zones are calculated. It shows a discrete set of damage levels and distances characterizing the consequences of the accident.

The probabilistic approach for the chosen level of damage does not determine the critical value of a hazard, but shows the probability of this level of damage depending on the distance to the center of the accident. This probability is calculated on the basis of probit functions of the general form $\operatorname{Pr}=a+b \cdot \ln (F)$

, where $F$ is a function that characterizes the level of a hazardous factor, and the coefficients $a$ and $b$ are selected separately for each hazardous factor.

In the case of a spill fire, the recommended probit function $\operatorname{Pr}\left(x, x_{0}\right)$ which is given below (eq. 3).

The methods of the listed engineering calculations are given in normative documents. Of course, with their help it is possible to obtain results that are effectively used in determining the compliance of facilities with industrial safety requirements.

However, ever-growing data volumes significantly increase the calculation time [9-11]. Optimization and acceleration of calculations can be achieved by using relational databases and using the previously described method for optimizing the calculation of the double integral [12, 13, 8].

In [8], the calculations of the effects of explosions of air-fuel mixtures during accidents on linear equipment were optimized using the probit function as an example to assess the likelihood of destruction of industrial buildings in which buildings are to be demolished.

In this paper, in contrast to the combustion mode "Combustion of a fuel-air mixture with the formation of excess pressure" considered in [8], the "Spill fire" mode is considered. This combustion mode has its own characteristics. In particular, during a spill fire, the main hazard is the intensity of thermal radiation $q$ $\left(\mathrm{kW} / \mathrm{m}^{2}\right)$ [14]. At the same time, for practical calculations, the special recommended probit function is used, which includes very bulky multi-parameter expressions.

\section{Materials and methods}

For practical implementation, industrial and fire safety involves obtaining quantitative assessments of the effects of harmful factors of potential accidents at hazardous production facilities with fire and explosive substances.

To solve the problem of assessing the impact level of a possible accident at the observation point $M_{0}$, the use of probit functions is justified [15-20].

According to [1], the probability $Q$ of the level of exposure at the observation point $M_{0}$ of a possible accident that occurred at point $M$ is found from the value of $\mathrm{Pr}$ :

$$
Q\left(M, M_{0}\right)=\frac{1}{\sqrt{2 \pi}} \cdot \int_{-\infty}^{\operatorname{Pr}-5} \exp \left(-\frac{t^{2}}{2}\right) d t
$$

For the case of a pipeline (i.e. for a long distance), industrial equipment is considered as a segment $l$ of the curved line. Then, for an accident with a specific type of depressurization and type of combustion, the potential probability $Q_{n}\left(M_{0}\right)$ is determined:

$$
Q_{n}\left(M_{0}\right)=p_{y} \cdot \int_{l} \psi(M) Q\left(M, M_{0}\right) d l,
$$

where $\psi(M)$ is the specific probability of a particular type of depressurization at the point $M$ of the curve $l$, year ${ }^{-1} \mathbb{W}^{-1}$, and $p_{y}$ is the conditional type of combustion.

In [1], a rectilinear fragment of a pipeline with an explosive liquid is considered on the plane, presented as a straight line segment $y=a x+b$ connecting the points $M_{s}\left(x_{s}, y_{s}\right)$ и $M_{e}\left(x_{e}, y_{e}\right)$. In practical calculations, usually $\psi(M)=$ const . A technique is proposed for optimizing the calculation of $Q_{n}\left(M_{0}\right)$, based on the formula:

$$
\begin{aligned}
Q_{n}\left(M_{0}\right)=p_{y} \psi & \sqrt{1+a^{2}} \cdot\left[x_{\text {end }} \cdot Q\left(x_{\text {end }}, x_{0}\right)-x_{\text {st }} \cdot Q\left(x_{\text {st }}, x_{0}\right)-\right. \\
& \left.-\frac{1}{\sqrt{2 \pi}} \cdot \int_{x_{S t}}^{x \text { end }} x \cdot \exp \left(-\frac{\left(\operatorname{Pr}\left(x, x_{0}\right)\right)^{2}}{2}\right) \cdot \operatorname{Pr}_{x}^{\prime}\left(x, x_{0}\right) d x\right]
\end{aligned}
$$

In formula (2), the quantity $\operatorname{Pr}_{x}^{\prime}\left(x, x_{0}\right)$ can be obtained by calculating the derivative in explicit form. As a rule, the function $\operatorname{Pr}\left(x, x_{0}\right)$ has a complex form, so you should use well-known mathematical packages that provide the possibility of analytical differentiation.

The field of potential risk is also a characteristic to be evaluated [21, 22, 10].

\section{Results}

We use the obtained expression (eq. 2, [1]) to calculate the level of exposure to thermal radiation during a spill fire.

In [1], formula (2) was applied to calculate the level of exposure to an air-fuel mixture explosion using a 
probit function to assess the likelihood of destruction of industrial buildings in which buildings are to be demolished.

Now, we calculate the level of the impact of the spill fire using the probit function Pr recommended in [2] to estimate the probability of thermal radiation damage:

$$
\operatorname{Pr}\left(x, x_{0}\right)=-12.8+2.56 \cdot \ln \left(t \cdot q^{(4 / 3)}\right),
$$

where $t$ is the effective exposure time (s),

$$
t=t_{0}+\frac{x}{u},
$$

$t_{0}$ is the characteristic time for which a person detects a fire and decides on their further actions (s) (can be taken equal to 5),

$x$ is the distance $(\mathrm{m})$ from the person's location to the safe zone (the zone where the intensity of thermal radiation is less than $4 \mathrm{~kW} / \mathrm{m}^{2}$ ),

$u$ is the average speed of a person to a safe zone, $\mathrm{m} / \mathrm{s}$ (assumed to be $5 \mathrm{~m} / \mathrm{s}$ );

$q$ is the intensity of thermal radiation $\left(\mathrm{kW} / \mathrm{m}^{2}\right)$ ([16]):

$$
q=E_{f} \cdot F_{q} \cdot \tau
$$

$\tau$ is the atmospheric transmittance,
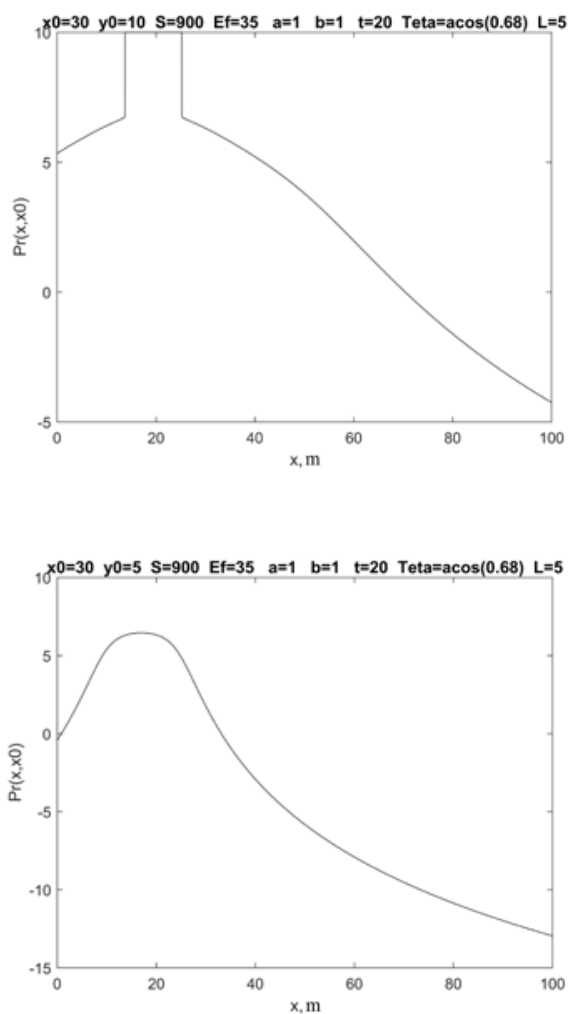

Fig.1. The graphs of the functions $\operatorname{Pr}(x)$ and

\section{Discussion}

Let us evaluate the degree of acceleration of calculations when using formula (2) in comparison with direct calculation by formula (1).

We estimate the degree of acceleration as follows. Randomly generate 1000 sets of source values. We carry out calculations according to formulas (1) and

$$
\tau=\exp \left[-7 \cdot 10^{-4}\left(\mathrm{R}_{\mathrm{m}}-\frac{\mathrm{d}}{3}\right)\right],
$$

$d$ is the effective diameter of the spill (m),

$R_{m}$ distance from the geometric center of the spill to the point of observation (m).

$E_{f}$ is the average surface intensity of thermal radiation $\left(\mathrm{kW} / \mathrm{m}^{2}\right)$,

$F_{q}$ is the angular coefficient of irradiation.

The value of $F_{q}$ is calculated using cumbersome formulas, which can be found in [2].

To implement formula (2), the derivative $\operatorname{Pr}_{X}^{\prime}\left(x, x_{0}\right)$ was analytically calculated using the mathematical package MATLAB R2016. The resulting expression is not given because of its bulkiness.

Figure 1 shows the graphs of the functions $\operatorname{Pr}(x)$ and $\frac{d \operatorname{Pr}(x)}{d x}$ for two values of the observation points $M_{0}^{1}(30,10)$ and $M_{0}^{2}(30,5)$ for the values of the parameters: $S=900, E_{f}=35, a=1, b=1, t=20$, $\Theta=\arccos (0.68)$.
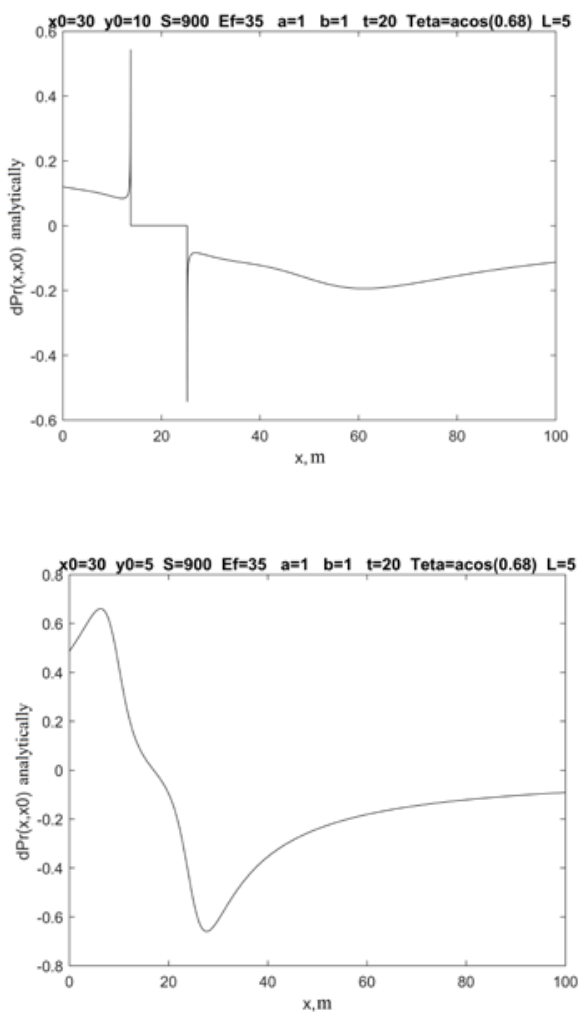

$\frac{d \operatorname{Pr}(x)}{d x}$ for two values of the observation points.

(2), fixing the execution time of calculations $T_{1 i}$ and $T_{2 i}$, respectively, for each of the formulas for the ith data set. Let us take the ratio $M T R_{i}=T_{1 i} / T_{2 i}$, $\mathrm{i}=1 . .100$ as the Multiplicity of Time Reduction. We also calculate the difference in the values of potential probabilities:

$$
D Q_{i}=\left|Q_{n} 1_{i}-Q_{n} 2_{i}\right|
$$


Where $Q_{n} 1_{i}$ are the values calculated by the formula (1), and $Q_{n} 2_{i}$ are the calculated by the formula (2).

Let us consider a rectilinear fragment of a pipeline with a flammable liquid, presented as a straight line segment $y=a x+b \quad$ connecting the points $M_{s}\left(x_{s}, y_{s}\right)$ and $M_{e}\left(x_{e}, y_{e}\right)$.

We form random sets of initial parameters. Moreover, it is obvious that the calculation speed does not depend on the quantities $M_{s}\left(x_{s}, y_{s}\right), p_{y}$,
$\psi(M)=$ const , and the coefficient of the line $b$, therefore, in all random sets we will assume that they are unchanged: $x_{s}=0, p_{y}=0.2, \psi=1.0 e-7, b=1$.

The rest of the data sets are taken as evenly distributed in the intervals: $a \in[0.001,1], x_{0} \in[0,2000]$, $y_{0} \in[0,2000]$, flame length $L \in[0.5,100]$, angle of deviation of the flame from the vertical under the action wind $\Theta \in[0, p i / 2], E_{f} \in[5,250]$, pipeline length $L_{m p} \in[10,2000]$, effective exposure time $t \in[5,50]$. The number of sets is $N=1000$.

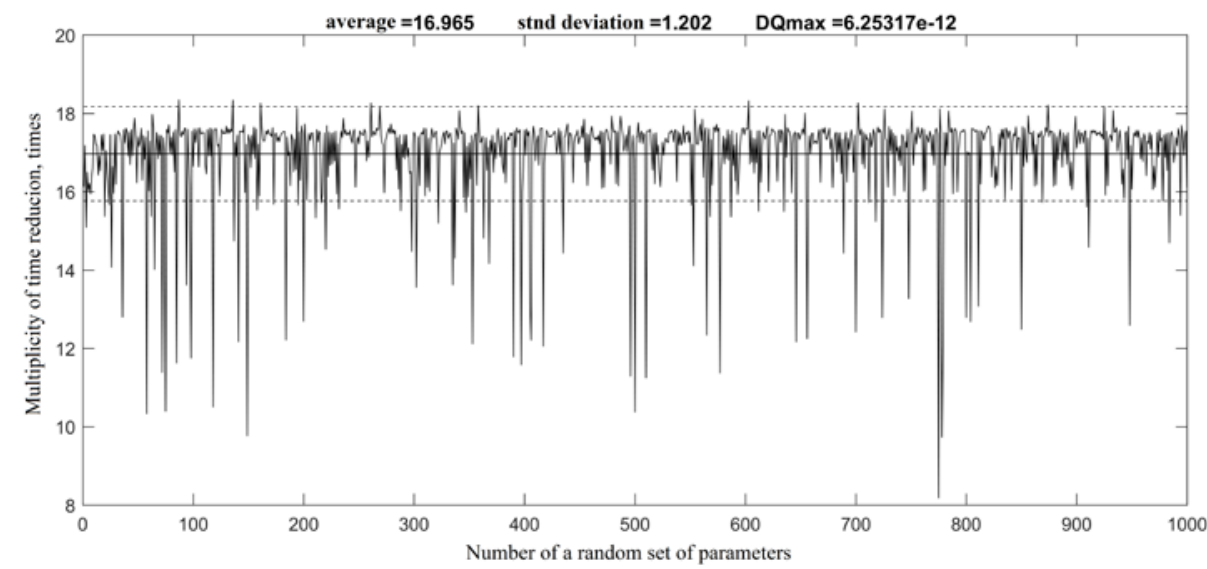

Fig.2. The graph of the values of the multiplicity of the reduction of the calculation time by the formula (2) in comparison with the calculation by the formula (1).

The calculations are implemented in the MATLAB R2016 package. Integrals were calculated using the built-in "integral” function with standard accuracy by default for the package. Figure 2 shows the calculated maximum deviation:

$$
D Q_{\max }=\max _{i=1 . .1000}\left|Q_{n} 1_{i}-Q_{n} 2_{i}\right|=6.25317 e-12
$$

\section{Conclusion}

The paper analyzes the problems of industrial (fire) safety. An assessment was also made of the totality of the data constituting the "Emergency Scenario", and allowing to set the task of carrying out the calculations necessary for the practical implementation of the safety of a hazardous production facility.

A technique is proposed for numerically solving the problem of calculating the potential probability of exposure to hazardous factors of a possible accident on extended industrial equipment. The process of optimizing the calculation of the effects of the fires of the spill has been implemented. For the thousands of random sets of source data considered, it is shown that the average calculation acceleration is 16.965 (times) with a standard deviation of 1.202.

Thus, the application of formula (2) gives a significant reduction in the calculation time of $Q_{n}\left(M_{0}\right)$.

It is advisable to use the results obtained to reduce time when carrying out resource-intensive calculations in the fields of industrial and fire safety.

\section{References}

1. Federal Law of 21.07.1997 N 116-FZ "On Industrial Safety of Hazardous Production Facilities" (as amended and supplemented on 07.03.2017).

2. The order of the Ministry of Emergency Measures of Russia from 04.11.2004 № 506 "About the statement of the standard safety passport of dangerous object".

3. The order of the Ministry of Emergency Measures of Russia from 10.07.2009 № 404 "The method of determining the calculated values of fire risk at production facilities" (in the edition of Order No. 649 of the Ministry of Emergency Measures of the Russian Federation of December 14, 2010).

4. RD 03-496-02 "Methodological recommendations for the assessment of damage from accidents at hazardous production facilities".

5. RD 03-418-01 "Methodological instructions for conducting risk analysis of hazardous production facilities".

6. Order Rostechnadzor No. 144 of April 11, 2016 On Approval of the Safety Manual "Methodological Framework for Hazard Analysis and Risk Assessment of Accidents at Hazardous Production Facilities".

7. E.A. Saltanaeva Information Aspects of the Emergency Scenario Concept in the Field of Industrial Safety. International Journal of Advanced Studies Vol. 8, № 4-2, 117-121 (2018). 
8. E.A. Saltanaeva, A.V. Maister Optimization of calculations of the impact of explosions of fuel-air mixtures in case of accidents on linear equipment, Far East Con-2019, in press.

9. Y. Li, M. Chen, Z. Dou, X. Zheng, Y. Cheng, A. Mebarki A review of cellular automata models for crowd evacuation. Physica A: Statistical Mechanics and its Applications 120752 (2019).

10. E.Salzano, V.Cozzani The analysis of domino accidents triggered by vapor cloud explosions. Reliability Engineering and System Safety 90(2-3), pp. 271-284 (2005).

11. P.K. Kythe, M.R.Schäferkotter: Handbook of computational methods for integration. 2004.

12. R.A. Abdulatipov, I.R. Hanafiev, E.V. Savel'ev, E.A. Saltanaeva Metody i abstrakcii jazykov programmirovanija $\mathrm{v}$ zadachah raboty $\mathrm{s}$ bazami dannyh. Sovremennye nauchnye issledovanija $i$ razrabotki № 9 (26), 36-41 (2018).

13. V.V. Cehanovskij, V.D. Chertovskoj: Upravlenie dannymi. Uchebnik. - Jelektron, tekstovye dan. SPb.: Lan' 2015 - ISBN 978-5-8114-1853-4: B. c.

14. M.A. Taimarov, E.A. Saltanaeva, R.V. Akhmetova, R.G. Sungatullin, Al zubaydi ali nalib salih: Heat flows from the torch in boilers with various layout burners, Izvestiya Vysshikh Uchebnykh Zavedenii. Energy issues Vol. 19 (2017). No. 9-10. S. 50-58.

15. “Occupational safety standards system. Fire safety of technological processes. General requirements. Control methods ". The national standard of the Russian Federation GOST R 12.3.047-2012. Approved by order of the Federal Agency for Technical Regulation and Metrology of December 27, 2012 N 1971-st.

16. "The method for determining the calculated values of fire risk at industrial facilities." Approved Order of the Ministry of Emergency Situations of Russia of 10.07.2009 No. 404, rev. Order of the Ministry of Emergency Situations of the Russian Federation dated 14.12.2010 №649.

17. E. Zarei, M.J. Jafari, F. Dormohammadi, V. Sarsangi: The role of modeling and consequence evaluation in improving safety level of industrial hazardous installations: A case study: Hydrogen production unit. Iran Occupational Health 10(6), 29-41 (2014).

18. J. Casal: Evaluation of the Effects and Consequences of Major Accidents in Industrial Plants. Second Edition 2017.

19. R. Vázquez-Román, J.-H. Lee, S. Jung, M.S. Mannan: Optimal facility layout under toxic release in process facilities: A stochastic approach. Computers and Chemical Engineering 34(1), 122133 (2010).

20. D. Drysdale An Introduction to Fire Dynamics. Third Edition 2011.

21. F. Stinger Handbook of sinc numerical methods. 2016.
22. Z. Dou, A. Mebarki, Y. Cheng, X. Zheng, J. Jiang, Y. Wang, Y. Li, J. Li Review on the emergency evacuation in chemicals-concentrated areas. Journal of Loss Prevention in the Process Industries 60, pp. 35-45 (2019). 